\title{
Importance of enzyme immobilization for human health
}

\author{
Zeki Yalcinkaya $^{1 *}$, Hakan Turan ${ }^{1}$, Halit Demir ${ }^{1}$
}

\begin{abstract}
In this review, we aimed to emphasize the importance of immobilized enzymes for human health in shed light on recent literature. In addition to our clinical experiences, some literature studies on immobilized enzymes were evaluated. Shortly, The immobilized enzymes bind to a specific region physically by using mediator enzymes, and shows catalytic activities repeatedly and continuously without losing their catalytic activities. In other words, enzyme immobilization is the trapping or binding of the insoluble form of the enzyme or the carrier agent to itself. Compared to free enzymes in solution, immobilized enzymes are tougher and more resistant to environmental changes. Some immobilized enzymes are also used in various industries. Immobilization techniques are generally used in industrial processes, diagnostics, bio-affinity chromatography and biosensors applications. As recently, immobilized enzymes have begun to be used in dissolving blood clots and clearing wounds.
\end{abstract}

Key words: Enzymes, immobilized, health, chemical reaction

\section{Introduction}

Enzymes are biocatalysts that provide a great efficiency by hiding chemical reactions in living organisms. Enzymes are biochemical catalysts that perform the transformation of chemical reactions in living organisms (1). Immobilized enzymes are made water insoluble by the help of insoluble support materials. The first industrial use of immobilized enzymes has reported by Chibata and co-workers in 1967 (2). Immobilized enzymes are not only used for enzymes, but can also be used in cells such as microbial cells, plant and animal cells. In studies conducted, enzyme immobilization is frequently used in diagnostic, bioaffinity chromatography and biosensor procedures $(3,4)$.

Many methods are available for enzyme immobilization. Immobilization enzyme has useful applications in various industrial fields (5). Pectin degrading enzymes are used in the food industry to clarify fruit juices, to facilitate filtration in fruit juice production, in the presence of galacturonic acid, the starting material for the synthesis of vitamin $C$, in the wine industry, in the extraction of oils, in pigments and in cellulose fibers as functional food ingredients in coffee and tea fermentation that are used for new applications in the production of oligosaccharides $(6,7,8,9)$.

In this study, we aimed to explain the importance in health of immobilized enzymes

\section{Conclusion}

Immobilized enzymes refers to enzymes physically confined or localized in a certain defined region of space with retention of their catalytic activities, and which can be used repeatedly and continuously $(10,11)$.

Immobilized enzymes can be used in process the various such as, medicine, microbial resistance, low cost, chemical durability,thermostability,high capacity of enzyme $(12,13)$. Immobilized enzymes are still most commonly used because it is the easiest to perform and the least expensive. Both organic and inorganic materials such as porous glass, cellulose, silica gels and hydro gels are used for preparation of immobilized enzymes $(5,14,15)$.

The main advantages of immobilization are the separation of the enzyme from the reaction solution easily in order to stop the reaction. Thus, it's crucial to utilize effort and material sources for each operation in each processing cycle and for stopping the enzyme activity; sudden heating, the addition of inhibitor or other processes are not required.

It is highly beneficial to reduce the catalyst input cost in large amounts in order to supply the utility of immobilization process which can be used for a long time. Immobilized enzymes are more stable and longer half-life than the free enzymes. The advantage of separating enzyme from the product; is to re-use the enzyme repeatedly and particularly to avoid the

Received 20-09-2017 Accepted 28-09-2017 Available Online 30-09-2017

1 Yuzuncu Yil University, Faculty of Science, Department of Chemistry, Van, TR

* Corresponding Author: Zeki Yalcinkaya E-mail: zeki@yyu.edu.tr Phone: +90 4322101000 
enzyme from toxicity, antigenic or to prevent the product from contaminations of medical circumstances by removing time, effort, cost, labor and material requirements and enabling the enzymes to be used in the same process together without focusing on their different optimum conditions; advantages of continuous operation, high and always the same quality of production, operation facilities, low labor costs, easily controllable conversion rates during retention are also advantages of enzyme separation from the product. Also, recent studies indicate that it's not necessary to prepare reagent since according to the conditions in which immobilized enzymes last longer, and as predicted for decay rates particularly for analytical purposes.

Immobilization disadvantages are the cost of immobilization and immobilization process equipment, also cost of materials that used in immobilization should be compared to the existing process. The availability and utility of immobilized enzyme in the process of performance in which the reduction of the complete disappearance of the enzyme activity enterprises the immobilization, also steric effects and diffusion restrictions especially the substrate and macromolecules of the product or when the insoluble form in some conditions exists.

Studies carried out by several authors using different methods have demonstrated that there is a correlation between stabilization and the number of covalent bonds to the matrix $(16,17,18)$. In another study, widely used application of the immobilization approach together with enzymes has been the enzymatic reactions on immobilized substrates. This approach facilitates the analysis of enzyme activities and mimics the performance of enzymes on e.g. cell walls (19). In the literature, Immobilization technique has applied on DEAE-cellulose by ionic bonding (20). In other study, A $\beta$-galactosidase enzyme has immobilized onto a gelatinized carboxymethylcellulose carrier using crosslinking chromium acetate (21). In addition, in the literature, Candida tropical xylose reductase enzyme has immobilized on chitosan beads by $\mathrm{Ni}^{+2}$ transition metal chelate binding method (22).

In recent years, the importance in health of immobilized enzymes increases day by day, especially in the food, nutrition and pharmaceutical sectors. Also, availability of immobilized enzymes in medicine become widespread and becomes popular for the diagnosis and treatment of some diseases.

In study one done immobilized PAL enzyme has been developed to reduce phenylalanine in phenylketonuric mice (23). Immobilized PAL is used both for the treatment of phenylketonuria disease and for the diagnosis of phenylalanine in urine (24). In literature study, a new method of immobilized PAL enzyme has developed for the diagnosis of phenylketonuria in urine (25).
This study provided some important information on some properties of immobilized enzymes and on their utility in health.

As a result; Immobilized enzymes have become especially increasingly important, in the food, nutrition and pharmaceutical sectors in recent years. The availability of immobilized enzymes has recently increased in world. In addition, immobilized enzymes should be widely used in the diagnosis and treatment of some diseases.

The more research should be done by using different methods in diagnosis and treatment on immobilized enzymes.

Conflict of Interest: The authors declare no potential conflicts of interest with respect to the research, authorship, and/or publication of this article.

Author's Contributions: ZY, HT, HD: Collecting of review data, writing and revision of article,

Ethical issues: All Authors declare that Originality of research/article etc... and ethical approval of research, and responsibilities of research against local ethics commission are under the Authors responsibilities. The study was conducted due to defined rules by the Local Ethics Commission guidelines and audits.

\section{References}

1. Stryer, L. Biochemistry; 1995, Freeman, New York.

2. Tosa T, Mori T, Fuse N, and Chibata I. Studies on continuous enzyme reactions. I. Screening of carriers for preparation of water-insoluble aminoacylase. Enzymologia. 1966; 31(4):214-24.

3. Guibault, GG, Kauffmann J M, and Patriarche J. Immobilized Enzyme Electrodes as Biosensors. In: Protein Immobilization. Fundamentals and Applications (Taylor, R. F., ed.), Marcel Dekker, New York, NT. 1991; pp. 209-262.

4. Taylor R F. Immobilized Antibody and Receptor Based Biosensors. In: Protein Immobilization. Fundamentals and Applications (Taylor, R. F., ed.), Marcel Dekker, New York, NY. 1991; pp. 263-303.224.

5. Savran A, Alkan S, Demir H, and H Ceylan. Applicaton of Natural Kaolin as Support for The Immobilization of Catalase from Bovine Liver, Asian Journal of Chemistry. 2006; 18, 413-418.

6. Telefoncu A. Enzimoloji. Yüksek Lisans Yaz okulu. 1997; 21-27 Eylül 1997.Kuşadası, Aydın, Türkiye.446 s.

7. Phutela U, Dhuna V, Sandhu S, Chadha BS. Pectinase and Polygalacturonase Production by a Thermophilic Aspergillus fumigatus Isolated from Decomposting Orange Peels. Brazilian Journal of Microbiology. 2005; 36:63-69.

8. Patıl S R, Dayanand A. Exploration of Regional Agrowastes for the Production of Pectinase by Aspergillus niger. Food Technol. Biotechnol. 2006; 44.289-292. 
9. Botella C, Diaz A, Ory I, Webb C, Blandıno A. Xylanase and Pectinase Production by Aspergillus awamori on Grape Pomace in Solid State Fermentation. Process Biochemistry. 2006; 42:98-101.

10. Katchalski-Katzir E. Immobilized enzymes: Learning from past successes and failures. Trends Biotechnol. 1993; 11, 471-478.

11. Beatriz M B, and Francisco Batista-V. Immobilization of Enzymes. Methods in Biotechnology: Immobilization of Enzymes and Cells. 2017; Second Edition Edited by: J. M. Guisan (C) Humana Press Inc., Totowa, NJ.

12. Burns RG. Soil Science Society of America, W. 1986; 439.

13. Alkan S, Gür T, Gür A, Uruc $H$ and Demir $H$ Immobilization of Catalase via Adsorption onto Natural and Modifed Montmorillant Analsim-Clay. Polish. Journal of Chem. 2009; 83, 2089-2095.

14. Baileey JE, and Ollis DF. Applied Enzyme Catalysis, McGraww-Hill International. 1986; Singapore, p.180.

15. Kennedy JF, Melo EHM. Immobilized enzymes and Cells Chem.Eng.Prog. 1990; 81.

16. Gabel D, Steinberg I, and Katchalski-Kazir E. Changes in conforma- tion of insolubilized trypsin and chymotrypsin, followed by fluorescence. Biochemistry. 1971; 10, 46614669 .

17. Koch-Schmidt A and Mosbach K. Studies on conformation of soluble and immobilized enzymes using differential scanning calorimetry. 1 . Thermal stability of nicotinamide adenine dinucleotide dependent dehydrogenases. Biochemistry. 1977a; 16, 2101-2105.
18. Koch-Schmidt A, and Mosbach K. Studies on conformation of soluble and immobilized enzymes using differential scanning calorimetry. 2. Specific ac- tivity and thermal stability of enzymes bound weakly and strongly to Sepharose CL 4B. Biochemistry. 1977b; 16, 2105-2109.

19. Gray CJ, Weissenborn MJ, Eyers E, Flitsch SL. "Enzymatic reactions on immobilised substrates". Chemical Society Reviews. 2013; 42 (15): 6378.

20. Mitz MA.. New soluble active derivatives of an enzyme as a model for study of cellular metabolism. Science. 1956; Vol.123; pp.1076-1077.

21. Sungur S, and Yildırım Ö.. Batch and Contınuous Hydrolysis of Lactose Using $\beta$-Galactosıdase Immobilized on Gelatın-CMC. Department of Chemistry and Biology, Faculty of Science, Ankara University, Polym-Plast. Technol. ENG.,1999; Vol.38; pp.821-829.

22. SuY, LiW, ZhuW, YuR, FeiR, WenT, CaoY, and Qiao D. Characterization of xylose reductase from Candida tropicalis immobilized on chitosan bead. African Journal of Biotechnology. 2010; Vol.9(31); pp.4954-4965.

23. Bourget $\mathrm{L}$, and Chang $\mathrm{T}$ M. Artificial cellmicroencapsulated phenylalanine ammonia-lyase. Appl. Biochem. Biotechnol. 1984; 10: 57 - 59.

24. Ateş S, Doğan N S. Properties of Immobilized Phenylalanine Ammonia Lyase and Investigation of its Use for the Prediagnosis of Phenylketonuria. Türk Biyokimya Dergisi. 2010; 35: 58-62.

25. Dogan NE. Utılization Of Immobilızed Enzyme In Diagnosis of Phenylketonuria. Gazı University Institute Of Science And Technology. 2008; (M. Sc. Thesis). Ankara. 